\title{
Exploration and Research of CMF Design in the Teaching of Product Design
}

\author{
ZHANG Hai-chao \\ Dalian University of Science and Technology, China
}

\begin{abstract}
Against the background that CMF design has a profound impact on product design, product design majors must also strengthen CMF teaching to achieve the goal of training modern industrial design talents. Based on this, this article analyses the application of CMF design in the teaching of product design majors, and proposes $\mathrm{CMF}$ teaching countermeasures from the aspects of curriculum system establishment, teaching content update, and practice platform construction, to provide a reference for people concerned about this topic.
\end{abstract}

\section{Introduction}

With the development of the design industry, more and more enterprises have established CMF departments to realize product design innovation and enhance product value and market influence under the guidance of aesthetic theory. Combining this trend, product design majors should also strengthen CMF design teaching, while demonstrating the value of CMF research, while providing students with product design R \& D and innovation space to promote students' quality and ability to meet the design industry development requirements.

\section{Professional development of CMF design and product design}

CMF is the process of color, material and surface decoration. In the process design, aesthetics should be regarded as the foundation, and innovation should be regarded as the criterion. As an interdisciplinary subject that involves knowledge in various disciplines such as color science, engineering materials science, and applied psychology, CMF design emphasizes the realization of targeted treatment of color, materials, and surface treatment processes, and promotes the design of products to show different effects. While strengthening brand differentiation, we can get value enhancement. In the context of the increasing speed of product market updates, product design takes many months or even years, so whether designers have the ability to strengthen the positioning of market trends is related to whether the final designed product can meet consumption. The demand for popular elements such as color, material and surface decoration. And CMF has excellent performance in the market, Haier, Gree, Xiao mi and other companies have successively established CMF work departments, complete product design through CMF innovation, and promote brand value [1]. Facing this trend, many universities including Tongji University and Donghua University have launched CMF-related courses to promote the professional development of product design. By opening a CMF design course, emphasizing product design innovation, professional teaching is required to meet the curriculum teaching goals of analyzing early design trends and achieving later design transformation, which can improve the professional teaching level and meet the development requirements of related industries. Therefore, in the training of product design professionals, students need to be guided to strengthen the CMF design process in order to improve students' understanding of color, materials and surface decoration technology, and to grasp the design trends of various elements, so that students will grow into modern industrial design needs.

\section{Application of CMF design in the teaching of product design}

\subsection{Lack of curriculum system}

Compared with developed countries and regions, the domestic CMF research started late, and no clear definition of CMF and related design standards have yet been formed. Affected by this factor, the domestic CMF education is still in the exploration stage. In the teaching of product design majors, although CMF courses have been established, the corresponding curriculum system has not been established. As a result, the CMF design theory learned by students does not conform to the trend of CMF application research. The curriculum teaching lacks systematics and is easy to be compared with traditional product design courses Knowledge overlap occurs. Failure to complete the top-level design of the course teaching has resulted in the fragmentation of 
knowledge points in the course teaching, which has brought some difficulties for students to understand the course content. As a result, students still focus on modeling and color design learning in CMF courses, ignoring materials, It is difficult to fully embody the aesthetic ideas and innovative concepts of CMF design when studying surface decoration process design. After studying for a semester, some students cannot even master the CMF design process, and it is difficult to use CMF knowledge to strengthen the analysis and grasp of design trends, which makes it difficult to fully reflect the value of the course.

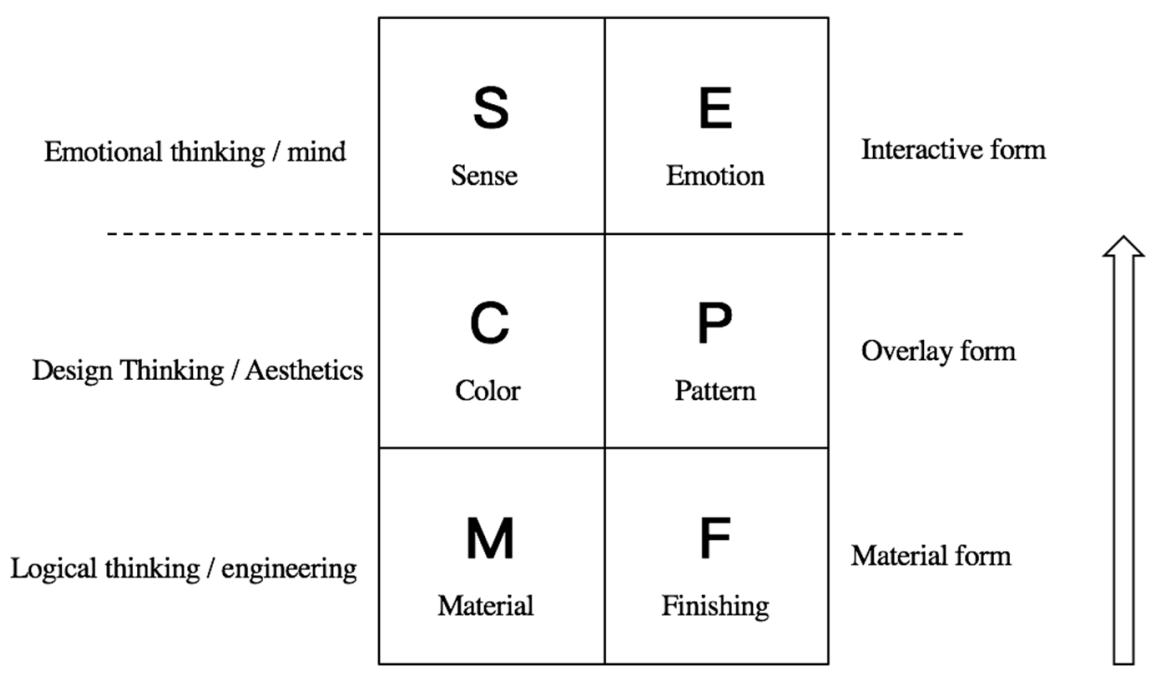

Figure 1. CMFPSE theoretical model

\subsection{Outdated teaching content}

At this stage, there are few professional books on CMF design, which is difficult to provide sufficient theoretical guidance for CMF course teaching. Actually, in the process of compiling course textbooks, it is necessary to complete the screening of relevant knowledge from different books, causing the course content to be mostly theoretical knowledge, while lacking pertinence, it is difficult to help students understand CMF design ideas. The content in some textbooks is outdated CMF knowledge, which focuses on product color or material design choices. Students are required to master the color and material attributes in the design field, and grasp related technical processes. There is a certain lag in the content, which cannot reflect the colors, materials, and surfaces. The close relationship between decorative crafts [2].

In contact with these principles, most students feel that the CMF teaching content is boring, difficult to remember and understand, which makes students more passive in the course learning, and the students' design thinking of attaching importance to product functions and appearance has not been changed. Due to the outdated content and the serious lack of new materials and new processes involved, CMF teaching cannot be given enough attention.

\subsection{Lack of practical learning}

In the absence of sufficient theoretical support, CMF course study still stays at the theoretical level, resulting in inadequate practical learning of students in CMF design, and it is difficult to cultivate product design trend analysis, design results transformation and other abilities. Although the product design majors of some colleges and universities have established CMF laboratories, they have only used the laboratories to demonstrate new materials and new processes, failing to guide students to participate in $\mathrm{CMF}$ design practices. In fact, $\mathrm{CMF}$ design practice includes multiple processes such as market research, color experiments, tactile experiments, and results testing. It not only requires a large amount of data support, but also needs to invest enough materials and equipment to ensure that students understand the development process of product design trends through experiments. , Experience the impact of different surface decoration elements on product application value. According to a survey of 200 students, as shown in Figure 2, everyone has different levels of requirements for knowledge points such as materials and processing technology, and wants to learn more about the basic theoretical knowledge of CMF. 


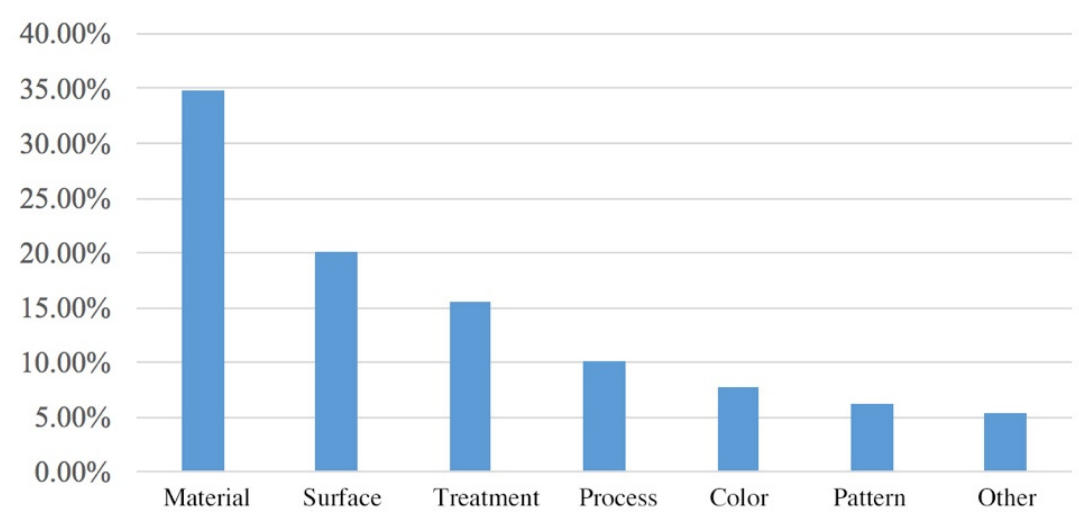

Figure 2. Statistics of students' demand for CMF knowledge points in teaching

\section{The application countermeasures of CMF design in the teaching of product design specialty}

\subsection{Establish CMF design curriculum system}

Combining the teaching of CMF courses, universities should also complete the establishment of a CMF design course system for product design majors to ensure that students can systematically complete CMF knowledge learning. Specifically, it is necessary to clarify the curriculum teaching goals, and then introduce the CMF knowledge system based on the goals. First of all, the course teaching needs to ensure that students grasp the relationship between CMF and product modeling and design, so the connotation of CMF should be introduced. By strengthening the comparison with the connotation of product modeling design, it can help students recognize that CMF design is a means to achieve product differentiation, transform the pursuit of value and appearance of product design into the pursuit of quality of life, and can use color, materials and surface decoration as It is the product "skin" that satisfies people's pursuit of beauty through reasonable design. Secondly, it is necessary to target the correct understanding of industrial design colors, materials, and surface treatment processes, and to introduce CMF design principles, including creating value experience, combining innovative design with user needs, extending the life cycle, etc., so that students can get a vision of product design, Strengthen research on product design trends. Finally, we need to establish teaching goals that require students to coordinate the use of color, materials, and surface decoration techniques, introduce CMF design methods, strengthen students' ability to use knowledge, practice and other aspects of ability training, and then enable students to grow into modern product design talents.

\subsection{Update product design teaching content}

As the theory and practice of CMF design are still in the stage of continuous exploration, the teaching content must be updated in the course of teaching in order to enable students to learn advanced design concepts and methods and learn how to ingeniously transform new materials and new processes into new ones. Design elements, forming the consciousness and ability to use aesthetic theory to complete innovative product design. In color teaching, the importance of color is explained. For example, the time for the human eye to obtain visual information is 0.67 seconds, and the proportion of color in visual information is $67 \%$. It is also necessary to explain the characteristics and principles of color collocation to guide students to strengthen color image learning Understand the image of product processing from the perspective of psychological perception, and learn how to grasp the user's sensory perception of product color characteristics, so as to meet the user's emotional needs through the rational use of color. In the teaching of materials, in addition to degrading the properties of various materials, it is also necessary to interpret popular new materials from the perspective of material imagery, to help students experience the new style that materials can bring to product design, and ensure that students can understand both physical and psychological levels. Grasp the differences in materials and make reasonable use of materials to give users a rich experience. In the teaching of surface decoration technology, teachers not only explain various new technologies, but also guide students to learn the effects of surface technology on decorative effects, product protection and service life, and promote students to use technology to improve the relationship between products, users and the environment. Which in turn shows the charm of the product by influencing the user's psychology.

\subsection{Building a Product Design Practice Platform}

Considering that CMF design includes user research, product positioning, design practice and other links, colleges and universities must also complete the construction of a professional design practice platform to provide students with the opportunity to use CMF knowledge to implement innovative product design, and then enable students to develop the ability to transform design results. In order to solve the problem of insufficient funding, universities and design companies can jointly create CMF laboratories, set up product design projects based on business needs, arrange professional teachers 
and students of product design to participate in project design activities, become corporate CMF designers, and carry out a series of practical activities. . Based on the information provided by the enterprise, teachers and students can use various methods, such as WeChat and QQ, to conduct surveys on corporate users and complete preliminary product research. Through newspapers, the Internet, and other channels, teachers and students can carry out market research practices, complete product design trend research, achieve in-depth analysis of product colors, materials, and surface decoration processes, establish links between users and products, and complete reasonable product positioning [3]. According to the set parameters of product color, touch and other parameters, teachers and students can carry out test experiments to further grasp product attributes, complete the redesign of color, materials and processing technology, and finally propose a feasible design solution through repeated verification. With the support of the enterprise, the design results can be transformed and verified by the market, so that students can gain practical ability training.

\section{Conclusion}

In summary, universities should also recognize the influence of CMF design on product design, establish a complete CMF design curriculum system in professional teaching, and systematically impart CMF knowledge. In practical teaching, we should also strengthen our grasp of the development trend of CMF, complete the updating of teaching content in time, and provide a way for students to learn new materials and new processes. The completion of the design practice platform can guide students to grasp the CMF design process, improve product design capabilities in practice, and then achieve the course teaching goals.

\section{References}

1. Wang Yuying, Pan Wei.Research on CMF's design innovation strategy and method [J]. Science \& Technology Innovation and Application, 2020 (01): 98-99.

2. Ai Qing. Preliminary Exploration of CMF Education Based on the Cultivation of Product Design Professionals [J] .Art Technology, 2019,32 (13): 207.

3. Chen Junbo, Zhang Li, Chu Peng. The influence and application of CMF design in product design [J]. Design, 2019, 32 (01): 108-109.

4. Zuo Hengfeng. Creative strategies and methods of CMF in design art [J]. Journal of Nanjing Academy of Art (Art and Design), 2018 (01): 193-200.

5. Matthew A. rod. CMF: final presentation of design [J]. Design, 2019, 32 (12): 25-26. 